\title{
Formação do Estado e da comunidade política em Timor-Leste - A centralidade do local
}

State Formation and Political Community in Timor-Leste - The Centrality of the Local

Formation de l'État et de la communauté politique au Timor-Leste - La centralité du lieu

\section{Anne Brown}

Tradutor: Victor Ferreira

\section{(C) OpenEdition}

\section{Journals}

\section{Edição electrónica}

URL: http://journals.openedition.org/rccs/5717

DOI: $10.4000 /$ rccs. 5717

ISSN: 2182-7435

Editora

Centro de Estudos Sociais da Universidade de Coimbra

\section{Edição impressa}

Data de publição: 1 setembro 2014

Paginação: 101-122

ISSN: 0254-1106

\section{Refêrencia eletrónica}

M. Anne Brown, «Formação do Estado e da comunidade política em Timor-Leste - A centralidade do local », Revista Crítica de Ciências Sociais [Online], 104 | 2014, posto online no dia 23 setembro 2014, consultado o 14 novembro 2019. URL : http://journals.openedition.org/rccs/5717 ; DOI : 10.4000/ rccs. 5717 


\title{
M. ANNE BROWN
}

\section{Formação do Estado e da comunidade política em Timor-Leste - A centralidade do local}

\begin{abstract}
Neste artigo aborda-se o entrelaçamento das práticas e dos valores institucionais tradicionais e liberais em Timor-Leste. Nele defende-se que as abordagens dominantes de se pensar a comunidade política e o Estado ignoram a importância de fontes de valores políticos da comunidade, excluindo-as de uma troca de ideias séria e não conseguindo proporcionar uma forma de se pensar seriamente na negociação da vida política através da diferença radical. Há, no entanto, uma "ecologia de relações" a tomar forma, que não é descrita pelos enquadramentos liberais nem pelos enquadramentos tradicionais. A natureza da comunidade política em Timor-Leste irá desenhar-se em função da forma como estes entrelaçamentos se vierem a desenvolver e do facto de serem negociados através de zonas de sombra não reconhecidas ou através de formas de intercâmbio mais acessíveis. O intercâmbio em torno de áreas de interação poderia dar substância à construção da nação e desenvolver a participação e a prestação de contas. Os sucos são fundamentais neste contexto.
\end{abstract}

Palavras-chave: diálogo político; formação do Estado; pós-colonialismo; Timor-Leste; vida política.

\section{Introdução}

Tal como acontece com muitos Estados pós-coloniais, o povo e o governo de Timor-Leste enfrentam a tarefa profundamente desafiadora de tecer em conjunto uma vida e uma linguagem política partilhada a partir da interação de culturas político-sociais e de lógicas de governação fundamentalmente diferentes (Hohe, 2002a). ${ }^{1}$ Desde a sua criação como um novo Estado (formalmente em 2002, após um período de administração

\footnotetext{
${ }^{1}$ Este artigo baseia-se numa série de períodos de investigação passados em Timor-Leste entre 2002 e 2011, investigando a construção da paz a nível local e o impacto da eleição das administrações dos sucos. A investigação foi realizada com associados de investigação timorenses, em particular Alexandre Gusmão, e que também incluiu, de 2009 a 2011, uma equipa da Universidade Nacional de Timor-Leste. Embora tenha viajado bastante pelo país, a equipa de investigação levou o trabalho a cabo em cada um dos 13 distritos de Timor-Leste. O seu trabalho está discriminado nas referências bibliográficas.
} 
das Nações Unidas desde o final de 1999), Timor-Leste tem-se caracterizado pela coexistência de normas liberais e de um modelo de governo burocrático-legal, com formas e valores de governação locais, genericamente tradicionais, e pela interação das trocas do mercado internacional com o que ainda é fundamentalmente uma economia de subsistência (Brown, 2009; Nixon, 2006). Na prática, estas lógicas estão inevitavelmente enredadas, moldando-se umas às outras e sendo remodeladas no processo de interação. No entanto, as mundividências em que estão inseridas e os modelos de prática que produzem permanecem em muitos aspetos profundamente divergentes. Estas diferenças vão para além da diversidade linguística e cultural que caracteriza Timor-Leste; mais precisamente, envolvem construções profundamente diferentes de comunidade, individualidade e obrigação, de autoridade, responsabilidade e economia, da natureza e do sagrado (Hicks, 2004).

No entanto, em sintonia com os paradigmas internacionais predominantes de construção do Estado e de construção da paz, as representações dominantes do Estado e da nação - da vida política de Timor-Leste concentram-se quase inteiramente nas instituições e nas elites do Estado (ou nas ameaças a estas instituições). Outras dinâmicas de poder aparecem na melhor das hipóteses como simplesmente "culturais", a serem geridas no âmbito dos termos do Estado burocrático-legal. Essa abordagem permanece profundamente enraizada internacionalmente, apesar da "viragem local" em algumas discussões teóricas e, em menor grau, políticas (Denney, 2013; OECD, 2010). Neste artigo defende-se que, ao não reconhecer devidamente "outras" construções de poder e de ações adequadas como fontes genuínas e formadoras da comunidade política, as abordagens centradas no Estado colocam os entendimentos de poder mais locais e comunitários fora da troca, negociação ou do controlo sério, tornando-os, assim, algo que está "escondido à vista de todos". Além disso, esta omissão torna-se um obstáculo aos esforços para compreender e negociar as interações das diferentes construções de poder, de valor e de riqueza, e dos seus efeitos sobre a liderança, as instituições, a governação e as vidas. Em muitas partes do mundo pós-colonial, a fricção e a confusão entre os modos liberais e os tradicionais de governação criaram zonas ambíguas que não são governadas por padrões de prestação de contas tradicionais nem burocrático-legais, escondidas do escrutínio e fervilhando com a manipulação oportunista e violenta (Boege et al., 2009; Ellis e ter Haar, 2004).

A coexistência de normas de governação é um desafio profundo, mas não constitui em si mesmo o problema. Pelo contrário, é a natureza e os 
efeitos particulares da "ecologia das relações" (Descola, 2013) criados pela sua interação que são importantes - que dinâmicas de poder são possíveis; quem é excluído; são ou não desenhadas as relações no sentido de se tornarem abertas à discussão e à troca, são ou não reconhecidas ou responsabilizáveis. A natureza da comunidade política em Timor-Leste e o caráter do seu funcionamento enquanto Estado são suscetíveis de ser fundamentalmente moldadas pela forma como estas lógicas entrelaçadas de governação se desenvolvem e são mobilizadas por diversos interesses. Além disso, estes envolvimentos são importantes não apenas para o governo central, mas estão em jogo talvez até mais intensamente ao nível das comunidades, das aldeias (Cummins, no prelo). Os processos de discussão e troca de ideias em torno de áreas concretas de interação poderiam dar substância aos esforços de construção da nação e aos valores democráticos da participação, da prestação de contas e do respeito que Timor-Leste abraçou constitucionalmente. Neste contexto, é importante que os valores comunitários e tradicionais dominantes sejam levados a sério como fontes genuínas da vida política e as aldeias como locais cruciais da prática de governação emergente e fundamentais para a experiência e o bem-estar das pessoas.

Neste artigo procede-se a uma reflexão sobre os fossos, tensões e entrelaçamentos existentes entre as práticas e os valores tradicionais e os liberais, com maior ênfase nas aldeias. Após um comentário sobre os termos, situa-se a discussão ao olhar rapidamente para o surgimento do novo Estado de Timor-Leste. Assinala-se a disjunção entre a abordagem liberal institucional centralizada à governação e a abordagem da comunidade, mas também se consideram os pontos fortes e fracos dos esforços para gerir essa disjunção: eleições, processos de consulta, o papel dos bens sociopolíticos e alguns esforços da comunidade local. Dada a importância das aldeias para a comunidade política emergente, neste artigo discutem-se aspetos da vida tradicional e comunitária. As eleições nas aldeias são um exemplo do crescente entrelaçamento de diferentes abordagens à governação e uma indicação da diversidade dos compromissos alcançados. As tradições podem em si mesmas ser entendidas como uma expressão de autodeterminação. A seguir, retoma-se uma discussão mais ampla sobre o exílio das "tradições" a partir da forma como o "Estado" e, por implicação, a comunidade política são comummente conceptualizados. Reflete-se sobre as abordagens mais relacionais e dinâmicas para a compreensão do Estado e enfatiza-se o desafio e a importância dos processos de envolvimento e intercâmbio para a construção da comunidade política através da diferença radical. 
A construção deste argumento em termos da própria governação institucional do Estado e da governação tradicional arrisca repetir a reificação de categorias, quando é mais frequente ser uma fusão dinâmica de vários elementos a dar forma às realidades no terreno. No entanto, chamar a atenção para os valores comunitários e tradicionais é uma resposta ao tratamento que eles recebem, que é muitas vezes pejorativo ou negligente. As mundividências tradicionais e práticas são entendidas aqui como dinâmicas e multidimensionais, com uma longa história de resiliência, remodelação, rejeição e incorporação (McWilliam, 2005, 2008). A governação liberal também constitui uma família de abordagens multiformes e opostas. O termo "local" é um termo aberto (Shaw e Waldorf, 2010). Refere-se, primeiro, ao governo local do suco. ${ }^{2} \mathrm{Nas}$ áreas rurais, é o suco que lida com a segurança e a subsistência quotidiana e é onde a maioria dos timorenses têm experiência direta da governação. O suco é um ponto de referência fundamental para a comunidade política em Timor-Leste e um local crucial de entrelaçamento da governação tradicional com a governação institucional do Estado. Embora as formas de governação do suco variem ao longo do país (Gusmão, 2012), em aspetos importantes o significado da governação do suco é mais "nacional” do que a do governo central, uma vez que são os valores e os mecanismos locais que suportam a ordem social e política a nível nacional. O "local" também aponta para valores e práticas tradicionais, que são locais no sentido de serem "do lugar", endógenos, mas também persistentes e de grande alcance, por um lado com uma diversidade considerável ao longo do país, mas partilhando fortes semelhanças familiares. No entanto, ser local não significa que os sucos ou as tradições estejam "espacialmente presos", existindo numa esfera diferente ou isolada das dinâmicas globais, internacionais ou nacionais (Appadurai apud Shaw e Waldorf, 2010: 6).

\section{O novo Estado de Timor-Leste}

A independência é uma conquista recente e duramente alcançada de Timor-Leste. O Estado e o governo centralizado são a forma disponível de afirmação da independência no sistema internacional e, para muitos timorenses, simbolizam a rejeição da opressão e da violência da era indonésia e representam afirmações de autodeterminação e esperança. Muitos timorenses fizeram grandes sacrifícios pessoais para votar no referendo de 1999 que levou à independência. Talvez como reflexo disso, continua a

\footnotetext{
${ }^{2} \mathrm{O}$ suco constitui a menor divisão administrativa de Timor-Leste e pode ser composto por uma ou mais aldeias (cf. http://timor-leste.gov.tl/?p=91).
} 
verificar-se um elevado nível de participação nas eleições nacionais. Desde a independência formal, em 2002, Timor-Leste realizou duas eleições parlamentares e testemunhou uma mudança de governo - uma conquista significativa. O próprio Estado pode ser visto como uma declaração de independência e de ser timorense, e as pessoas querem fazer parte dele (McWilliam e Bexley, 2008).

De acordo com a prática dominante internacionalmente, a construção do Estado em Timor-Leste tem sido altamente centralizada, primeiro sob a égide da ONU (UNTAET - Administração Transitória das Nações Unidas em Timor-Leste) e em seguida com os governos nacionais (Chopra, 2002; Soux et al., 2007). Respondendo à escala da destruição verificada em 1999, a comunidade internacional e a diáspora timorense que então regressou encararam a tarefa que tinham pela frente como "nada menos do que construir uma nova nação praticamente a partir do zero" (UNDP, 2000: 92). Este desafio inspirou esforços extraordinários por parte da elite timorense e da comunidade internacional para a construção de um Estado moderno - um esforço que se concentrou diretamente na construção da estrutura administrativa (Richmond e Franks, 2008). A extensão às áreas rurais foi dotada com poucos recursos (Chopra, 2002). A arena do Estado era uma nova esfera para os timorenses, e o estabelecimento de instituições governamentais viáveis tem sido importante. No entanto, "construir uma nova nação" não é o mesmo que estabelecer a estrutura administrativa, sendo que a falta de instituições estatais não é equivalente à ausência de uma comunidade política.

Longe de constituir um vácuo político, foi o movimento de resistência clandestina que restabeleceu inicialmente no terreno a governação local na sequência da devastação deixada pelos militares indonésios (AGLD, 2003). Trabalhando com as redes tradicionais, a resistência operava "uma estrutura de comando e controlo que [... era caracterizada por] uma durabilidade, coerência e flexibilidade local eminentemente adequadas à tarefa de manter os serviços básicos e a ordem social" (ibidem: 49). Em contraste, os esforços da UNTAET para gerir as regiões foram descritos como "governação de agência": organizada em torno dos requisitos de apresentação de relatórios da ONU e respondendo a uma burocracia centralizada de gestão de projetos (ibidem: 53). As formas de organização e de agência local que tinham contribuído para a sobrevivência e resistência foram reconhecidas nos esforços de construção do Estado como colorido cerimonial, "folclore" ou obstáculo para os valores liberais (Hohe, 2002a: 570). Em Díli, as administrações e programas governamentais foram estabelecidos com referência a modelos burocráticos internacionais, mas com pouca referência à sua capacidade de se envolver com o funcionamento 
das comunidades locais. Tal como um conselheiro ministerial timorense comentou:

Foi muito bom [a ONU e a comunidade internacional] terem vindo. [Mas...] entre as agências e instituições globais [... implementaram] mecanismos de cortar e colar. [...] Não se pode simplesmente chegar aqui com dinheiro [...]. Há aqui valores [...] que é preciso respeitar. (Entrevista, Díli, 2011)

Pode, pois, não ser apenas por uma questão de recursos que as instituições do Estado continuam a chegar pouco além da capital e que há uma profunda separação entre a vida urbana e a rural (Toome et al., 2012). $\mathrm{Na}$ prática, são poucas as estruturas estabelecidas em Timor-Leste que suportam as normas liberais ou que apoiam a sua integração na experiência das pessoas, embora tenham alguma circulação, em particular, mas não só, em áreas urbanas, e possam ser defendidas com paixão. A confusão entre a ordem social liberal e a tradicional também tem sido um desafio para Díli, uma vez que as estruturas materiais e sociais que podem apoiar na prática as formas liberais de ordem social são relativamente pouco desenvolvidas (Valenti, 2014), enquanto as altas taxas de migração urbana significam que os mecanismos de parentesco são relativamente fracos (Trindade e Castro, 2007).

A inclusão democrática nos intercâmbios que constituem a comunidade política nacional tem sido abordada em grande parte em termos eleitorais. Os timorense são claramente recetivos à oportunidade de participar na escolha da liderança (Toome et al., 2012). No entanto, as eleições nacionais continuam a ser uma forma "ténue" de compromisso. As eleições por si só não associam o exercício de liderança às preocupações, necessidades e aos valores da comunidade e não são capazes de superar a disjunção entre as instituições locais e as instituições burocrático-legais (Hohe, 2002b; dos Santos e da Silva, 2012). As eleições abrem a porta a conjuntos mais amplos de intercâmbio e a formas de prestação de contas necessárias para uma maior legitimidade substantiva. Sem estes intercâmbios, o poder de legitimação das eleições poderia ficar mais fraco. O governo também leva a cabo processos de consulta pública; "no entanto, os períodos de consulta são geralmente curtos e é divulgada pouca informação de antemão" (Wallis, 2012: 11). São significativos os desafios na criação de processos inclusivos de intercâmbio que não sejam movidos por agendas políticas específicas do governo (Tully, 1995).

Instituições como os sistemas de justiça podem trabalhar no sentido de unir a comunidade política, mas também podem resultar fraturados. 
Por exemplo, de acordo com os trâmites normais, casos criminais ou graves vão a tribunal em Timor-Leste, enquanto os casos menos graves são tratados através dos métodos tradicionais de gestão de conflitos. No entanto, como um Administrador de Distrito explicou,

na realidade, o sistema de justiça não funciona, por isso temos de usar os métodos tradicionais para ambos [crimes graves e menos graves], e isso tem raízes profundas na sociedade - vem dos nossos antepassados... [e] é mais eficaz... uma vez que o sistema de justiça é tão fraco, temos de usar o sistema tradicional. Bem... as estatísticas da criminalidade são muito baixas... Não é porque não haja problemas, mas porque usamos casas tradicionais para os resolver. (Entrevista com Administrador de Distrito, 2008)

Nas conversas nos ministérios e com as agências internacionais circula uma forma de falar de justiça, ao passo que no terreno circula outra bem diferente. Ambas têm coisas importantes a dizer, mas falham na interação. Um efeito não intencional desta falta de comunicação é que o intercâmbio sobre bens sociais e políticos fundamentais - neste caso a justiça, o que ela significa e o que as pessoas procuram nela - é subvertido, pelo menos entre as autoridades centrais e outras autoridades.

No entanto, são os intercâmbios acerca de bens fundamentais como a justiça, e não apenas as eleições, que fazem crescer a teia de relações e de linguagem partilhada entre governados e governantes e entre formas de governação. Existe um corpo de prática e de experimentação à volta destas interações que se acumula ao nível dos distritos e dos sucos. Os tara bandu, acordos tradicionais negociados no âmbito de um suco - e que cobrem muitas questões sociais, ecológicas e de recursos - constituem um canal para esse tipo de explorações. A polícia local pode fazer parte de um acordo tara bandu, mas o mesmo pode suceder com uma empresa local ou com os representantes distritais de um ministério. Os tara bandu são exemplos de elementos flexíveis, pragmáticos e dinâmicos das tradições. Laura Yoder (2007) documentou a cooperação entre os representantes distritais do ministério central responsável pela silvicultura e as comunidades locais - impressionante, na medida em que demonstra a aceitação por parte dos funcionários do ministério da tomada de decisões tradicionais e da imposição de sanções ao governo, e vice-versa -, embora existam também outros exemplos (Cummins, no prelo; McWilliam, 2008; Palmer e de Carvalho, 2008). Ao longo do tempo poderão surgir formas mais profundas de articulação a partir destes desenvolvimentos. 


\section{As ordens tradicionais e os sucos}

Os sucos adaptaram-se ao longo dos séculos a mudanças fundamentais de regime político. A grande diversidade dos sucos reflete a diferença cultural, linguística e geográfica, mas também as variações regionais nesta história de adaptação. O suco, incluindo as aldeias e as famílias, é a principal arena para as formas tradicionais de governação. Se as instituições do governo central têm relativamente pouca penetração nas regiões, os sucos, e as redes de clãs em que eles em grande parte assentam, suportam a ordem social, a produção de alimentos e o bem-estar para a maioria dos timorenses. No entanto, o governo central também chega à população rural em grande medida através dos sucos.

Timor-Leste é na sua maioria rural, com mais de $70 \%$ da população dependente da agricultura de subsistência num ambiente natural difícil. Nas áreas rurais, a maioria das pessoas vive em comunidades pequenas e dispersas, como aldeias ou localidades ainda mais pequenas, tendo por base os laços de parentesco. Apesar de alguns serviços prestados pela igreja, governo ou outras agências, estas são fundamentalmente comunidades de autoajuda (Grenfell et al., 2009). Os sistemas de crenças tradicionais estão incorporados na vida da família alargada, dando-lhes poder, durabilidade e alcance. O parentesco é estruturado através das uma ou "casas" - que estão ligadas internamente ao lugar e aos antepassados partilhados - e da rede de obrigações recíprocas que têm origem no casamento. A uma inclui os familiares vivos, mas também os que morreram e os que ainda não nasceram; inclui o mundo natural, mas também os espíritos (McWilliam, 2005). Esta teia mística tem forma concreta na uma lulik ou uma lisan: a casa sagrada ou secreta, onde se concentra a veneração dos antepassados e em que os lisan ou seja, os valores, práticas e relações adequados são ensinados e onde lhes é dada expressão (McWilliam, 2005; Tilman, 2012). Os lisan incluem a governação, mas a governação tal como incorporada no que é apreendido como uma unidade antiga com os antepassados, o mundo natural e o mundo invisível do espírito. Os antepassados têm grande importância nas uma, podendo as pessoas falar com os mortos regularmente. Eles estão onde começa a comunidade. Isto tem um significado fundamental para uma sociedade que ainda está a lidar com a perda da vida em larga escala.

A ordem social com base no parentesco suporta grande parte da gestão prática da vida quotidiana. No entanto, as redes de parentesco vão muito para além dos sucos individuais e formam a "base cultural e económica para a continuidade da sociedade timorense" (McWilliam, 2005: 38; Trindade e Castro, 2007). Os anciãos da casa desempenham tradicionalmente 
papéis importantes no suco, com formas particulares de responsabilidade (para os recursos naturais, justiça, saúde, etc.) associados a determinadas famílias (Ospina e Hohe, 2001; dos Santos e da Silva, 2012). As famílias exercem o poder (embora não de forma igual) e os sucos envolvem transações políticas constantes dentro e entre as aldeias do suco. Consenso e harmonia são altamente valorizados - a sobrevivência pode depender deles - mas pode haver divisões sérias no interior do suco, assim como entre eles, associadas à ocupação indonésia, à guerra civil que a precedeu, aos partidos políticos atuais ou a histórias mais antigas de conflito.

Tal como estes sucos tradicionais, também surgiram "novos" sucos constituídos por grupos mais heterogéneos de famílias e, por vezes, por grupos em que se misturam línguas diferentes em resultado da migração urbana ou do desalojamento de um grande número de timorenses por parte dos militares indonésios (Thu, 2008). Durante o domínio indonésio, muitos sucos costeiros absorveram os fluxos de migração forçada dos sucos de montanha, criando uma mistura de padrões de suco. Nos sucos genuinamente urbanos, já não é a necessidade de se organizarem em torno da produção de alimentos que determina as atividades. Verifica-se no entanto um conjunto de diferenças e mudanças entre os sucos em que os padrões tradicionais se mantêm substancialmente e aqueles que em grande parte registam novas configurações. Em 2004, num esforço para democratizar os sucos, o governo aprovou uma lei que instituiu eleições e estabeleceu conselhos formais nos sucos (dos Santos e da Silva, 2012). As eleições e as novas estruturas de liderança introduziram uma forte dinâmica na vida política destes. No entanto, a política e os padrões de autoridade nos sucos não se converteram simplesmente num guião que possa ser "lido" a partir das eleições ou que seja descrito pelas estruturas dos sucos. É impressionante a variedade de formas através das quais os padrões de liderança e de poder tradicionais e eleitorais interagem no contexto da governação local. A uniformidade superficial das estruturas dos sucos, através da qual o Estado procura tornar a vida sociopolítica nacional "legível" a partir do centro, cobre uma extraordinária variedade de adaptações e experiências (Gusmão, 2012; Scott, 1998).

Em sucos mais tradicionais, os ciclos agrícolas, culturais e de parentesco moldam bastante a ordem social (McWilliam, 2008). Ser eleito para um cargo nem sempre garante autoridade nestes contextos, e em alguns sucos os "líderes locais sem antecedentes de liurai [autoridade tradicional] tiveram dificuldade em manter a sua autoridade no exercício das suas atividades quotidianas" (Pereira e Koten, 2012: 227). Este é um desafio também enfrentado pelas mulheres eleitas para os Conselhos de Suco. 
Embora não seja comum, as mulheres podem deter funções de liderança substanciais, incluindo as de chefia do suco, mas essa posição deriva de outras fontes, seja a ascendência familiar ou a reputação obtida durante a resistência (Cummins, 2010). No entanto, os sucos também são centros administrativos para a distribuição de serviços e projetos - nem todas as atividades fazem parte dos ciclos de vida tradicionais dos sucos. Novas atividades podem abrir caminho a novas formas de liderança, como as que são proporcionadas pela eleição dos dirigentes, enquanto os novos sucos colocam novas questões de governação.

No entanto, a liderança eleita não está necessariamente associada a níveis mais elevados de participação - nalgumas aldeias a liderança eleita foi considerada como tendo uma participação reduzida (Pereira e Koten, 2012; Tilman, 2012). A visão de que o Chefe de Suco já não trabalha para toda a comunidade ou que já não é responsável perante ela, mas que distribui os recursos apenas pelos seus eleitores (ou familiares) contribuiu para a falta de participação e cooperação (entrevistas de 2011; Cummins, no prelo). A concorrência entre partidos (que já não é permitida de forma direta a nível dos sucos) também foi muitas vezes um fator de divisão (Gusmão, 2012).

Estas solicitações e circunstâncias concorrentes geram compromissos consideravelmente diferentes - embora o compromisso nem sempre seja alcançado. Um pequeno número de comunidades elege simplesmente o seu liurai tradicional como Chefe de Suco (por exemplo, em Viqueque e Oecussi). No entanto, é mais comum "embrulhar o velho sistema no novo" - para as autoridades tradicionais identificarem líderes que venham a trabalhar em estreita colaboração com eles, que são então "confirmados" através de um processo de eleição (dos Santos e da Silva, 2012; McWilliam, 2008). As autoridades tradicionais podem simplesmente "ungir" a escolha da comunidade, entregando o poder formalmente ao chefe eleito, e colaborando com base em diferentes formas de legitimidade. Esta ação não constitui um gesto formal para uma sociedade secular mas, sim, uma concessão ritual de autoridade cheia de significado para a comunidade (Gusmão, 2012). No suco urbano de Bairopite (em Díli), em comparação, a tradição não desempenha qualquer papel na escolha do chefe, embora a uma lisan dos habitantes originais da zona ainda seja chamada a desempenhar um "papel no [...] desenvolvimento, na paz e na estabilidade do suco" (Tilman, 2012: 201).

A independência em Timor-Leste desencadeou dois esforços extraordinários para dar vida à autodeterminação. Um tem sido a construção das estruturas de governo através das quais Timor-Leste afirma a sua soberania 
internacionalmente reconhecida; o outro tem sido o ressurgimento de dimensões mais visíveis da tradição - a reconstrução das uma lulik e a negociação dos tara bandu, entre outras. Durante a ocupação indonésia, muitos lugares de importância cultural e cosmológica foram destruídas pelas tropas indonésias e os principais aspetos da vida comunitária foram reprimidos. Com a independência, os aspetos fundamentais da vida tradicional têm sido renovados. Através destas rotas desafiadoramente diferentes, os timorenses têm vindo a reclamar o controlo do seu próprio espaço político. "O ressurgimento das leis e dos costumes tradicionais não constitui um 'retrocesso'... mas o reconhecimento da adaptação e da dinâmica em curso que informam os processos tradicionais de elaboração das leis que estão presentes na vida quotidiana das pessoas" (Palmer, 2007: 36).

A ligação poderosa entre a comunidade, a identidade cultural e o impulso para a autodeterminação pode ser ilustrado através dos comentários de um entrevistado, um empresário de um centro provincial:

Precisamos de manter [as práticas tradicionais] - aliás, temos de as manter. Caso contrário, o que é a independência? O que é que defendíamos antes e o que é que defendemos agora? Na nossa luta defendemos a nossa terra, a nossa cultura, as nossas florestas; se agora não defendermos a nossa cultura, a nossa independência não tem raízes, não tem alicerces. Muitas pessoas chegam com os seus costumes e ideias, mas nós também temos costumes e ideias. [...] Se [...] perdermos as nossas raízes e o nosso caminho, teremos perdido a nossa identidade [...]. Para que é que vencemos a luta? Por causa da nossa forte estrutura de [parentesco] [...], não digo que temos de glorificar tudo isso, mas temos de o reconhecer. Atualmente, estamos a ignorá-lo [...] Agora, os líderes modernos do governo usam os líderes tradicionais ao nível das bases para ganhar poder. Quando ganham poder, acabou-se [não se envolvem mais com eles]. (Entrevista, Same, 2008)

\section{Construindo o Estado}

A coexistência de diferentes lógicas de governação dá forma a muitos Estados. Trata-se de um fator fundamental na experiência pós-colonial e constitui o contexto de muito "desenvolvimento" (Baker e Scheye, 2007; Boege et al., 2009; Ellis e ter Haar, 2004). Apesar disso, a história da descolonização oferece pouco em termos de experiência positiva na negociação construtiva dessas diferenças. Uma das razões para essa falta de experiência positiva é a forma como essas interações foram definidas, não só nas políticas e práticas e nas abordagens mais duradouras à ciência política, mas no imaginário popular dentro e fora do Norte global. 
Em termos gerais, o que "vemos" ou "não vemos" no Sul global tem sido profundamente influenciado por uma polarização altamente normativa e reificada da "tradição" e da "modernidade". Nas formas mais fortes e difundidas dessa dicotomia, a tradição é tida como estática, retrógrada, irracional e violenta, enquanto a modernidade é identificada com a razão, o progresso e a ordem (Fukuyama, 2011; Smith, 2005; Tully, 1995). Numa narrativa mítica do progresso, a tradição torna-se, por definição, o passado obscuro deixado para trás. O ponto de chegada da narrativa política é o Estado, particularmente o Estado liberal moderno, e a dicotomia entre a tradição irracional e a modernidade esclarecida está incorporada nas representações populares do Estado. Não há aqui nenhuma sugestão de que esta dicotomia deva ser virada do avesso, de modo a que a tradição passe a ser vista como positiva e o Estado moderno como negativo. Pelo contrário, o que se rejeita é a presunção normativa automática, as categorias essencializadas e a trajetória narrativa naturalizada "das trevas para a luz". As estruturas e os atos justificados pela "tradição" podem ser violentos e opressivos, assim como o podem ser os que são identificados com a "modernidade" (Richards, 2005). Também não se trata de uma posição relativista - podem ter-se políticas, critérios e métodos para julgar e lidar com as práticas, e as comunidades precisam de os desenvolver, mas é preciso que isso seja feito com base no reconhecimento e no envolvimento em diferentes cosmologias morais de governação (Brown, 2002; Tully, 1995).

Esta polaridade está profundamente enraizada no nosso entendimento da comunidade política e do Estado, formando atitudes e ferramentas. Os entendimentos dominantes da política estão fundados no Estado, e fornecem poucos meios para pensar seriamente em formas alternativas de governação, enquanto o Estado é condição sine qua non da democracia, dos direitos humanos, da segurança e do bem-estar. Como refere um texto influente na construção da paz, a construção de uma autoridade central do Estado é o passo fundamental na sequência de conflitos violentos, uma vez que, "na ausência do primado da lei aplicado por uma autoridade central, [...] a coexistência pacífica [...] iria desintegrar-se num 'estado de selvajaria sem lei'” (Paris, 2004: 49). Na mesma linha, num artigo que integra o Failed States Index 2013, afirma-se que "para a segurança humana sustentável, o processo só termina com a construção do Estado" (Haken e Taft, 2013: 23).

Por isso, os esforços de desenvolvimento e de construção da paz, sejam os dos doadores ou os das capitais pós-coloniais, têm ignorado repetidamente as abordagens à governação de base local, não as considerando 
relevantes para a comunidade política moderna, ou classificando-as como ameaças ao Estado que é necessário erradicar (Fukuyama, 2011). Em alternativa os Estados tentam incorporar, mas também instrumentalizar, formas locais de governação, prestando pouca atenção aos efeitos que essa incorporação pode ter na governação tradicional ou em processos e instituições estatais. Nesta abordagem, as instituições do Estado constituem o domínio prevalecente e global da política e do bem público, enquanto a governação tradicional é encarada como o domínio da sociedade (maioritariamente rural) - familiar, de pequena escala e paroquial (Shaw e Waldorf, 2010). Esta narrativa transmite uma aspiração, mas pode obscurecer mais do que revela. Não fornece uma forma de pensar seriamente sobre as complexidades da vida política através da descontinuidade radical: sobre o jogo do poder, a distribuição de recursos, bem como a determinação de valores relevantes e formas partilhadas de prestação de contas. Até agora, não há nenhuma forma partilhada de falar sobre estas interações, dos contextos em que surgem e das dinâmicas políticas e institucionais que geram, que de algum modo se adeque aos efeitos que geram.

Para os doadores, mesmo quando o papel da governação tradicional na prestação de bens sociais é reconhecido, o envolvimento com corpos não estatais tende a ser visto como demasiado problemático. Para o Department for International Development (DFID), por exemplo, os desafios do envolvimento "giram em torno do caráter iliberal de alguns atores informais e da natureza burocrático-liberal do DFID, o que o predispõe para certas formas de envolvimento que privilegiam o Estado e, simultaneamente, problematizam atores informais, incluindo os chefes" (Denney, 2013: 6). No entanto, o resultado dessas abordagens é afastar as questões de saber se, como e em que ordem a segurança, a justiça, a responsabilização ou a participação são prestadas e por quem, e não explorar o potencial de envolvimento construtivo (Baker e Scheye, 2007; dos Santos e da Silva, 2012).

O trabalho tem-se baseado na assunção de que as instituições do Estado são as fontes de ordem política. Em resultado disso, a comunidade internacional tem enfatizado o reforço ou a transferência para os Estados e para as eleições da arquitetura institucional, encarada como fundamental (Paris, 2004; Richmond, 2005). De acordo com este entendimento (globalmente weberiano), o Estado é identificado com as instituições do governo e da lei, que são tidas como distintas da sociedade, mas que a ordenam. Como Tanje Hohe comentou em relação à missão inicial da ONU em Timor-Leste, a "Administração de Transição construiu instituições com base no pressuposto de que não havia conceitos e ideias fortes a nível local, 
e que havia apenas que 'ensinar' democracia à população" (Hohe, 2002a: 570). Seja qual for a aplicabilidade de tais abordagens para os Estados em que as instituições governamentais e societais já partilham uma cultura política, elas são inadequadas para questões relacionadas com a formação do Estado e da nação, em particular perante diferenças profundas.

Uma comunidade política pode antes ser entendida como um efeito das relações entre as instituições do Estado, as instituições da sociedade e as ordens sociais (Cudworth et al., 2007). Conforme refere Marc Galanter, comentando sobre a transferência de instituições legais, "assim como a saúde não se encontra sobretudo nos hospitais nem o conhecimento nas escolas, também a justiça não se encontra sobretudo nas instituições oficiais que aplicam a justiça" (Galanter, 1981: 3). Pelo contrário, são as relações entre a arquitetura jurídica e as "instituições, culturas, tradições, costumes e práticas" em que essa arquitetura opera que estabelecem uma forma funcional de justiça (Krygier e Mason, 2008: 5). As instituições políticas, económicas e legais formais trabalham em grande parte porque estão enraizadas em redes de práticas sociais, que, por sua vez, as instituições ajudam a regular. Reduzir o Estado às principais instituições e a formação do Estado à transferência institucional significa que pouca atenção é dada à forma como essas instituições podem estar relacionadas com o seu contexto sociopolítico ou construir relacionamentos com entidades e práticas já existentes. Isso encoraja a centralização do poder e dos recursos na capital, e processos estatais que têm poucas razões para olhar à sua volta. Embora o quadro genérico de uma instituição possa, de facto, ser importado, os processos e as relações através dos quais se envolve com o seu contexto - através dos quais se remodela e é remodelado por entendimentos locais de comunidade (ou da saúde ou da justiça, etc.) ou é levado pela dinâmica política existente - são no entanto fundamentais para o tipo de trabalho que a instituição irá realizar e para os efeitos que virá a ter (Boege et al., 2009).

\section{Envolvimento e relacionamento}

Trabalhar em diferentes lógicas de governação e de construção do poder gera desafios específicos à qualidade do intercâmbio e das relações entre os membros da comunidade, os decisores e as instituições - até que ponto são as pessoas capazes de articular as suas preocupações e necessidades ou explicar as decisões, quem e o que é que é ouvido ou não, o que é visto e o que se torna invisível, quem é capaz de fazer parte do intercâmbio e quem não é. O governo eficaz e legítimo, e certamente o governo participativo, requer um tipo de "linguagem" comum por parte da comunidade política. 
Serem "incluídos" e capazes de participar na "conversa" sobre a ordem política - metaforicamente "ter uma palavra a dizer" ou, mais importante, ser ouvido - é o que os timorenses poderiam esperar da independência: autodeterminação e democracia. Para fazer parte é necessário ser capaz de perceber a ordem e a linguagem dominante no seio da comunidade política. No entanto, expandir a conversa política constitui um desafio muito particular quando existem diferentes linguagens sobre aquilo que devemos uns aos outros. Como James Tully afirmou sobre as relações entre os indígenas canadianos e os colonos, a vida política participativa em regiões marcadas por construções profundamente diferentes de comunidade política exige um diálogo consciente entre os diferentes mundos da vida (Connolly, 2000; Tully, 1995). Neste contexto, o envolvimento exige muito mais do que os esforços habituais da consulta popular, em que as agências do Estado geralmente "ouvem" os contributos apenas de acordo com os seus próprios quadros de referência (Brown, 2002; Tully, 1995). Internacionalmente, há uma longa história de marginalização e de omissão sistémica das formas endogâmicas de base comunitária da ordem social por parte das estruturas estatais (Smith, 2005).

No entanto, não são só a participação e a inclusão que exigem um envolvimento consciente. A interseção das lógicas divergentes de prestação de contas e obrigação está diretamente relacionada com questões de corrupção; diferentes expetativas de legitimidade e autoridade afetam o exercício da liderança; abordagens à ordem política que excluem largos setores da população incentivam a divisão, o empobrecimento, a insegurança e a corrupção, e assim por diante (Brown, 2009). O entrelaçamento de lógicas de governação molda os tipos de práticas que predominam, seja formalmente, seja informalmente ou mais profundamente escondidos da vista. Muitas vezes não é claro de antemão o modo como essas lógicas afetam e remodelam na prática a função de cada um (Cummins, 2010). O esforço para substituir as formas tradicionais de tomada de decisão e prestação de contas por abordagens burocrático-legais, por exemplo, pode contribuir para a erosão da tomada de decisão tradicional, sem fornecer alternativas com autoridade genuína, localmente legítimas, ou bem compreendidas (Ellis e ter Haar, 2004; Pereira e Koten, 2012). As formas burocrático-legais de governação e as formas locais de governação também geram as suas próprias formas de exclusão, que são tão propensas a agravar essa exclusão como a neutralizar-se uma à outra (Cummins, 2010). Ou seja, está a tomar forma uma ecologia das relações que não é descrita nem pelos termos de referência institucionais liberais nem pelos termos de referência tradicionais. As dinâmicas de poder que emergem desta ecologia das relações irão determinar 
quem e o que se encontra habilitado ou excluído em diferentes áreas de atividade. $\mathrm{O}$ facto de estas interações serem exploradas e negociadas através de zonas de sombra não reconhecidas ou através de formas mais acessíveis de intercâmbio será de importância crucial para a natureza da comunidade política em Timor-Leste.

Este tipo de diálogo entre a diferença não se coaduna facilmente com os processos e exigências de segurança da maioria das operações do governo central. É um desafio profundo para as instituições do Estado entrar em intercâmbios nos dois sentidos, ou em "conversas de improviso" que implicam ouvir para além dos limites das estruturas normalizadas, em vez de entregar "mensagens" a populações supostamente submissas (Duffield, 2007). No entanto, é provável que o custo venha a ser grande se não se perseverar neste trabalho demorado e incerto. É que em Timor-Leste grande parte da justiça, do bem-estar social e da segurança alimentar de que o Estado depende tem por base não as instituições de governo, mas em grande parte as formas tradicionais de autoridade (Grenfell et al., 2009). A interface do próprio governo nacional de Timor-Leste com as ordens sociais tradicionais representa uma nova era extremamente importante. Após gerações de colonização e ocupação, os timorenses podem exigir um governo que esteja orientado para eles e podem esperar um intercâmbio político mais genuíno.

Construir um conjunto mais substancial e reconhecido de relações em torno, por exemplo, da forma como a justiça poderá funcionar, da segurança alimentar, ou da descentralização implica um envolvimento muito maior. A segurança alimentar ou a justiça não são serviços que existam no vazio, fazem parte de contextos de valor e de significado intersubjetivo, e vão à raiz das expetativas de cada pessoa; envolvem debates que fazem parte do que constitui o intercâmbio democrático sobre o que é necessário, o que é significativo e o que é exequível.

\section{Conclusão}

Grande parte do trauma político nas zonas pós-coloniais pode ser causado no mundo das sombras que inclui as estruturas de poder do Estado e a realidade das comunidades. Pensar na comunidade política do Estado poderia, em vez disso, começar pelas redes de relações que ligam as ordens sociais, as instituições e as normas, das quais as instituições do Estado constituem uma parte. Essa mudança de perspetiva evidencia uma gama diferente de perguntas e ênfases. Coloca em primeiro plano a necessidade de prestar atenção às realidades das comunidades e de um envolvimento sério com elas. Enfatiza a construção de uma linguagem comum por parte 
da comunidade política no contexto da negociação em torno de valores, práticas e bens sociais e políticos. Para Timor-Leste, significa levar os sucos a sério, não apenas como destinatários de serviços ou de um projeto de construção do Estado, mas como centrais para a comunidade política, e isso significa prestar atenção à governação tradicional. Como José Magno e António Coa referiram, "a democracia assenta na comunidade e as comunidades vivem dentro da sua cultura" (2012: 173).

A governação tradicional não é liberalismo incipiente; levar a sério a tradição pode parecer implicar um enfraquecimento dos valores, como os direitos humanos, que muitos procuram num Estado liberal. No entanto, a experiência indica que as práticas tradicionais, embora conservadoras, não são estáticas, podendo ser criativas e adaptáveis. Algumas práticas tradicionais podem e devem ser desafiadas através de esforços para trabalhar contra a violência e a marginalização. No entanto, a defesa dos direitos humanos também inclui o reconhecimento dos direitos indígenas e coletivos, e por isso implica entrar nos intercâmbios demorados e difíceis que procuram trabalhar contra a violência ao mesmo tempo que se envolvem seriamente com as normas, práticas e circunstâncias locais (Brown, 2002; Tully, 1995). É importante não romantizar a vida tradicional, mas é igualmente importante não idealizar as instituições liberais (Brown, 1995). As instituições do Estado também geram violência e marginalização - todos os participantes podem ter algo a aprender com os outros.

Uma melhor compreensão da vida do suco poderia significar uma melhor previsão dos impactos da legislação, uma melhor orientação dos serviços e projetos, e uma maior atenção àquilo que as pessoas têm a dizer. As ligações já existentes poderiam ser reconhecidas e valorizadas, para que possam ser revistas e para que se possa aprender e construir a partir delas, sem que sejam estritamente geridas de forma centralizada. Isto poderia abrir um processo de formação do Estado a partir da base. Construir uma "linguagem partilhada" da comunidade política não significa que não haja discordâncias sérias, nem que as diferenças efetivas sejam superadas ou que se consiga partilhar todos os aspetos da forma como a comunidade política é entendida. Nem o reconhecimento do papel da governação tradicional na ordem e no sentido coletivo exige a integração da tradição no governo. Exige, sim, a elaboração ao longo do tempo de processos mutuamente inteligíveis para o envolvimento aberto com as comunidades e hábitos de apoio de diálogo e de escuta. O processo de intercâmbio pode ele próprio mudar os participantes, de forma subtil ou mais radical. Tais hábitos já existem em Timor-Leste, desenvolvidos ao longo de todo o espectro da vida política, mas a sua função e importância não é "encarada" nos termos da construção 
do Estado internacional, e por isso não é valorizada ou desenvolvida. No entanto, esses intercâmbios são essenciais para os caminhos lentos e confusos, mas produtivos através dos quais as populações experimentam elas próprias a partilha na comunidade política e pelos quais as estruturas e os mecanismos que permitem e gerem a evolução dessa comunidade evoluem. A governação democrática, responsável e voltada para o bem-estar das pessoas pode situar-se precisamente aqui, no modo como essas explorações e negociações tomam forma.

Tradução de Victor Ferreira

Recebido a 23.02.2014

Aprovado para publicação a 16.07.2014

\section{Referências bibliográficas}

AGLD - Administração para Governo Local e Desenvolvimento (2003), "Local Government Options Study: Final Report”. Dili: AGLD.

Baker, Bruce; Scheye, Eric (2007), "Mulit-layered Justice and Security Delivery in Post-conflict Fragile States", Conflict, Security and Development, 7(4), 503-528.

Boege, Volker; Brown, M. Anne; Clements, Kevin; Nolan, Anna (2009), "On Hybrid Political Orders and Emerging States: What is Failing - States in the Global South or Research and Politics in the West?", Berghof Handbook Dialogue Series, 8, 15-35.

Brown, M. Anne (2002), Human Rights and the Borders of Suffering: The Promotion of Human Rights in International Politics. Manchester: University of Manchester Press.

Brown, M. Anne (2009), "Security, Development and the Nation-Building Agenda - East Timor", Conflict, Security \& Development, 9(2), 141-64.

Brown, Wendy (1995), States of Injury: Power and Freedom in Late Modernity. Princeton: Princeton University Press.

Chopra, Jarad (2002), "Building State-Failure in East Timor", Development and Change, 33(5), 979-1000.

Connolly, William E. (2000), “The Liberal Image of the Nation', in Ducan Ivison; Paul Patton; Will Sanders (orgs.), Political Theory and the Rights of Indigenous Peoples. Cambridge: Cambridge University Press, 183-198.

Cudworth, Erika; Hall, Tim; McGovern, John (2007), The Modern State: Theories and Ideologies, Edinburgh: Edinburgh University Press.

Cummins, Deborah (2010), "Democracy or Democrazy? Local Experiences of Democratization in Timor-Leste", Democratization, 17(5), 899-919.

Cummins, Deborah (no prelo), Local Governance in Timor-Leste: Lessons in Postcolonial Statebuilding. Abingdon, Oxon: Routledge. 
Denney, Lisa (2013), “Liberal Chiefs or Illiberal Development: The Challenge of Involving Chiefs in DFID's Security Sector Reform Programme in Sierra Leone”, Development Policy Review, 31(1), 5-25.

Descola, Phillipe (2013), The Ecology of Others. Chicago: Prickly Paradigm Press. dos Santos, Abel; da Silva, Elda (2012), "Introduction of a Modern Democratic System and its Impact on Societies in East Timorese Traditional Culture", Local-Global: Identity, Security, Community, 11, 206-221.

Duffield, Mark (2007), Development, Security and Unending War: Governing the World of Peoples. Cambridge: Polity Press.

Ellis, Stephen; ter Haar, Gerrie (2004), Worlds of Power: Religious Thought and Political Practice in Africa. London: Hurst and Company.

Fukuyama, Francis (2011), The Origins of Political Order: From Prehuman Times to the French Revolution. New York: Farrar, Straus and Giroux.

Galanter, Marc (1981), "Justice in Many Rooms: Courts, Private Ordering, and Indigenous Law”, Journal of Legal Pluralism, 19(3), 1-47.

Grenfell Damian; Walsh, Mayra; Trembath, Anna; Norohona, Carmeneza; Holthouse, Kym (2009), Understanding Community: Security and Sustainability in Four Aldeia in Timor-Leste. Melbourne: The Globalism Research Institute, RMIT.

Gusmão, Alex (2012), "Electing Community Leaders: Diversity in Uniformity", Local-Global: Identity, Security, Community, 11, 180-191.

Haken, Nate; Taft, Patricia (2013), "The Dark Side of State Building: South Sudan”, Failed States Index 2013. Foreign Policy and The Fund for Peace. Consultado a 23.08.2014, em http://library.fundforpeace.org/library/cfsir1306-failedstatesindex2013-061.pdf.

Hicks, David (2004), Tetum Ghosts and Kin, Fertility and Gender in East Timor. Illinois: Waveland Press [2 ${ }^{\mathrm{a}}$ ed.].

Hohe, Tanja (2002a), "The Clash of Paradigms: International Administration and Local Political Legitimacy in East Timor”, Contemporary Southeast Asia, 24(3), 569-589.

Hohe, Tanja (2002b), “Totem Polls: Indigenous Concepts and 'Free and Fair' Elections in East Timor”, International Peacekeeping, 9(4), 69-88.

Krygier, Martin; Mason, Whit (2008), "Interpersonal Violence, the Rule of Law and its Enforcement," paper apresentado no Global Development Network Conference, em Brisbane, Austrália, 29-31 de janeiro.

Magno, Jose da Costa; Coa, Antonio (2012), "Finding a New Path between Lisan and Democracy at Suku Level”, Local-Global: Identity, Security, Community, 11,166-179. McWilliam, Andrew (2005), "Houses of Resistance in East Timor: Structuring Sociality in the New Nation", Anthropological Forum, 15(1), 27-44.

McWilliam, Andrew (2008), "Customary Governance in Timor-Leste”, in David Mearns (org.), Democratic Governance in Timor-Leste: Reconciling the Local and the National. Darwin: Charles Darwin University Press, 129-142. 
McWilliam, Andrew; Bexley, Angela (2008), "Performing Politics: The 2007 Parliamentary Elections in Timor-Leste”, The Asia-Pacific Journal of Antbropology, 9(1) 66-82.

Nixon, Rod (2006), "The Crisis of Governance in New Subsistence States”, Journal of Contemporary Asia, 36(1), 75-101.

OECD (2010), “The State's Legitimacy in Fragile Situations: Unpacking Complexity”. Consultado a 01.12.2012, em http://www.oecd.org/dac/incaf/44794487.pdf.

Ospina, Sofi; Hohe, Tanja (2001), "Traditional Power Structures and the Community Empowerment and Local Government Project - Final Report”. Dili: World Bank.

Palmer, Lisa (2007), "Developing Timor-Leste: Recognising the Role of Custom and Tradition”, SSEE Research Paper, 1, 35-40.

Palmer, Lisa; de Carvalho, Demetrio (2008), "Nation-building and Resource Management: The Politics of 'Nature' in Timor-Leste”, Geoforum, 39(13), 21-32.

Paris, Roland (2004), At Wars End: Building Peace After Civil Conflict. Cambridge: Cambridge University Press.

Pereira, Martinho; Koten, Madalena Lete (2012), "Dynamics of Democracy at the Suku Level”, Local-Global: Identity, Security, Community, 11, 222-235.

Richards, Paul (2005), "New War, An Ethnographic Approach”, in Paul Rochards (org.), No Peace, No War: An Anthology of Contemporary Armed Conflicts. Ohio: Ohio University Press, 1-24.

Richmond, Oliver (2005), The Transformation of Peace. Hampshire: Palgrave Macmillan. Richmond, Oliver; Franks, Jason (2008), "Liberal Peacebuilding in East Timor: The Emperor's New Clothes?”, International Peacekeeping, 15(2), 185-200.

Scott, James (1998), Seeing Like a State. New Haven/London: Yale University Press. Shaw, Rosalind; Waldorf, Lars (2010), Localizing Transitional Justice: Interventions and Priorities After Mass Violence. Stanford: Stanford University Press.

Smith, Linda Tuhiwai (2005), Decolonizing Methodologies, Research and Indigenous Peoples. London/New York: Zed Books e Dunedin: University of Dunedin Press.

Soux, Susan; Gairdner, David; Marstein, Sigurd (2007), Review of Development Cooperation of Timor Leste. Oslo: Scanteam Norad.

Tilman, Mateus (2012), "Customary Social Order and Authority in the Contemporary East Timorese Village: Persistence and Transformation”, Local-Global: Identity, Security, Community, 11, 192-205.

Thu, Pyone Myat (2008), "Land Forgotten: Effects of Indonesian Re-Settlement On Rural Livelihoods In East Timor", in David Mearns (org.), Democratic Governance in Timor-Leste: Reconciling the Local and the National. Darwin: Charles Darwin University Press, 143-159.

Toome, Emily; Grenfell, Damian; Higgins, Kathryn (2012), "Local Perspectives on Political Decision-Making in Timor-Leste”, Research Report. Melbourne: Globalism Research Centre, RMIT. 
Trindade, Jose; Castro, Bryant (2007), "Rethinking Timorese Identity as a Peace Building Strategy: The Lorosa'e - Loromonu Conflict from a Traditional Perspective". Final Report to GTZ/IS. Consultado a 23.08.2014, em http://www. indopubs.com/Trindade_Castro_Rethinking_Timorese_Identity.pdf .

Tully, James (1995), Strange Multiplicity: Constitutionalism in an Age of Diversity. Cambridge: Cambridge University Press.

UNDP (2000), Building Blocks for a Nation: The Common Country Assessment for East Timor. Dili, Timor-Leste: UNDP.

Valenti, Alix (2014), “Building States Without Building Nations”, Pacific Geographies, 41, 15-19.

Wallis, Joanne (2012), "A Liberal-local Hybrid Peace Project in Action? The Increasing Engagement between the Local and the Liberal in Timor-Leste”, Review of International Studies, 38(4), 735-761.

Yoder, Laura Meitzner (2007), "Hybridising Justice: State-Customary Interactions over Forest Crime and Punishment in Oecusse, East Timor", The Asia Pacific Journal of Anthropology, 8(1), 43-57. 
